\title{
Root caries: A geriatric challenge
}

\section{Próchnica korzenia - problem gerostomatologiczny}

\author{
Shiji Dinakaran ${ }^{A-F}$, Anupama S. Gopinathan ${ }^{B, D, E}$ \\ Department of Conservative Dentistry and Endodontics, Government Dental College, Thiruvananthapuram, Kerala, India \\ A - research concept and design; $\mathrm{B}$ - collection and/or assembly of data; $\mathrm{C}$ - data analysis and interpretation; \\ $D$ - writing the article; $E$ - critical revision of the article; $F$ - final approval of the article
}

\section{Address for correspondence \\ Shiji Dinakaran}

E-mail: shijidinakaran@gmail.com

\section{Funding sources}

None declared

Conflict of interest

None declared

Received on May 1, 2017

Reviewed on June 23,2017

Accepted on July 12, 2017

\begin{abstract}
Root caries is an important problem of concern for the elderly population in many countries. Due to its rapidly progressing nature and occurrence in areas of limited visibility, these lesions often go unnoticed unless they become symptomatic. Multiple systemic diseases, poor oral hygiene coupled with reduced manual dexterity of this age group add to the severity of the challenge. Limitations of available biomaterials along with reduced accessibility and isolation make the restoration of such dental lesions a clinical challenge also for dentists. Routine dental checkups and regular monitoring of risk factors can significantly reduce the occurrence of such caries to a major extent.

This article reviews the contemporary literature concerning the clinical features, etiology, risk factors and prevention of root caries. The main topic of the work is the electronic search of literature related to root caries; it was carried out in MEDLINE PubMed database using MeSH terms "root caries", "etiology"," "prevention".
\end{abstract}

Key words: risk factors, prevention, restoration, root caries

Słowa kluczowe: czynniki ryzyka, zapobieganie, odbudowa, próchnica korzeni

DOI

$10.17219 / \mathrm{dmp} / 75872$

Copyright

○ 2017 by Wroclaw Medical University

and Polish Dental Society

This is an article distributed under the terms of the

Creative Commons Attribution Non-Commercial License

(http://creativecommons.org/licenses/by-nc-nd/4.0/) 
Root caries is a multifactorial dynamic disease process that involves the interaction of the host, bacteria and nutrients, along with modifying or protective factors, resulting in the demineralization of a tooth. It was virtually the only form of caries seen in the aboriginal population in Papua-New Guinea. ${ }^{1}$ An examination of ancient skulls has revealed that root caries was more common than enamel caries in ancient man (Egyptian, North American Indian, Early Anglo Saxon). Today, in primitive societies such as certain natives of New Guinea highlands and aborigines of India, has been observed as the major cause of tooth loss. ${ }^{2}$

These soft, rapidly progressing destructive lesions are either confined to the root surface or involve undermining the enamel at the cementoenamel junction. Often, it is seen close to or within $2 \mathrm{~mm}$ of the cementoenamel junction. ${ }^{3}$ Root caries lesions that occur closely adjacent to or within $2 \mathrm{~mm}$ of the crest of gingiva are considered to be active, whereas lesions that occur farther from the gingival crest are more likely to be arrested. ${ }^{4}$ These lesions usually have less well-defined margins, are u-shaped in the cross section, often asymptomatic and have rapid progression. They can occur in areas of abrasion, erosion, abfraction, or as primary root caries or recurrent caries. ${ }^{5}$

Root caries progresses at about twice the rate of coronal caries because the critical pH of dentin is 6.7. Cementum covering the root surface is extremely thin near the cementoenamel junction, so it provides less resistance to acid attack. Apatite crystals of dentin and cementum are smaller in size than the enamel, and so the reactive surface is bigger. ${ }^{6}$ The loss of cementum increases the rate of penetrating the root by the lesion and also increases calcium and phosphate loss from the tooth surface. ${ }^{7}$ Early root caries tends to be diffuse and track along the cementoenamel junction on the root surface. More advanced root lesions enlarge toward the pulp. ${ }^{8}$

Evidence suggests that either facial or interproximal surfaces are more affected by root caries. ${ }^{9}$ The proximal root surface near the cementoenamel junction is often unattended by routine oral hygiene procedures because of the concave contours and occasional roughness at the termination of the enamel. These factors along with gingival recession lead to proximal root surface caries. Among the mandibular teeth, molars are more often affected, whereas in the case of maxillary teeth, the anteriors are more affected. ${ }^{10}$

In 1980, Root Caries Index (RCI) was introduced to overcome the limitations of DFS (Decayed, Filled Surface) index, since DFS index does not consider the number of tooth surfaces at risk of caries. ${ }^{11}$ It is calculated using the formula below and is expressed as a percentage:

$$
\text { Root Caries Index }=\frac{\begin{array}{c}
\text { number of root surfaces } \\
\text { with root caries }
\end{array}}{\begin{array}{c}
\text { number of root surfaces } \\
\text { with gingival recession }
\end{array}} \times 100 \text {. }
$$

The prevalence of root caries in the age group of 50-64 was found to be 3 times higher compared to 20-34 age group. ${ }^{12}$ Initially, Actinomyces sp. was believed to be the pathogen responsible for initiating root caries. ${ }^{2}$ Later, some studies suggested that Lactobacillus casei/paracasei/rhamnosus and Psuedoramibacter alactolyticus are associated with root caries. ${ }^{13}$ With advancing age, as a result of reduced immunity and systemic problems, oral microflora changes. Proteolytic bacteria represent $40 \%$ of microbes in root caries lesions. ${ }^{14}$ A recent study has found Propionibacterium acidifaciens, Streptococcus mutans, Olsenella profusa, Prevotella multisaccharivorax and Lactobacillus crispatus to be more associated with root caries. ${ }^{15}$

\section{Classification of root caries}

International Caries Detection and Assessment system (ICDAS) classifies and detects root caries based on the following criteria:

- color (light/dark brown/black);

- texture (smooth/rough);

- appearance (shiny/glossy, matte/non-glossy);

- perception on gentle probing (soft/leathery/hard);

- cavitation (loss of anatomic contour). ${ }^{16}$

In order to detect and classify root caries using ICDAS criteria a community periodontal index (CPI) probe should be used by the examiner. One score will be assigned per root surface. The facial/mesial/distal/lingual root surfaces of each tooth should be classified as follows:

Code $\mathrm{O} \rightarrow$ Root surface does not exhibit any unusual discoloration or surface defect, has normal surface contour.

Code $\mathrm{E} \rightarrow$ Root surface cannot be visualized directly or by gentle air-drying.

Code $1 \rightarrow$ Clearly demarcated areas on root surface or at the cementoenamel junction that is discolored but no cavitation present (loss of anatomic contour $<0.5 \mathrm{~mm}$ ).

Code $2 \rightarrow$ Clearly demarcated area on root surface or at cementoenamel junction that is discolored and has cavitation $(\geq 0.5 \mathrm{~mm})$.

Code $3 \rightarrow$ Cavitated ( $>0.5 \mathrm{~mm}$ depth) carious root surface which is soft/leathery.

Code $4 \rightarrow$ Cavitated ( $>0.5 \mathrm{~mm}$ depth) carious root surface which is hard/glossy indicating arrested/inactive caries.

Code $6 \rightarrow$ Extensive caries involving at least half of the tooth surface and reaching the pulp.

Code $7 \rightarrow$ Filled root with no caries.

\section{Risk factors for root caries}

Since root caries is a multifactorial disease, several intraoral, behavioral and population related factors may increase an individual's risk of developing root caries. 
Some of these factors are modifiable, whereas others are uncontrollable. ${ }^{17}$ Most studies have shown that the majority of root caries are primary lesions. This indicates that controlling/modifying risk factors can prevent caries. ${ }^{18}$ Risk factors can be intraoral or extraoral. The most common intraoral risk factor for root caries in adults is increased gingival recession leading to exposed roots. ${ }^{17}$ From clinical findings it can be assumed that an individual with a high risk of coronal caries has a higher chance of developing root caries, indicating that risk factors for both type of caries are more or less the same.

Xerostomia, resulting from chronic medication and radiation therapy, increases the risk of root caries. Drugs such as antipsychotics, sedatives, barbiturates, antihistamines reduce salivary flow and increase caries risk. ${ }^{19}$ Some studies indicate that low buffering capacity, low salivary immunoglobulin A, low salivary calcium and phosphate may also be associated with increased risk of root caries. As we age, our immune system weakens and less antimicrobial immunoglobulin is produced and found in the saliva. The level of serum immunoglobulin IgG and IgM is significantly reduced in older individuals. This may contribute to the increased susceptibility of elderly individuals to oral diseases. ${ }^{20}$

A diet high in refined carbohydrates, poor general and dental health are also risk factors contributing to the development of root caries. Both the quantity and frequency of sugar consumption are crucial factors in the development of root caries, similarly as in the case of coronal caries. Other intraoral risk factors include periodontal disease, periodontal surgery, unrestored coronal caries, partial dentures associated with plaque accumulation and gingival recession on abutment teeth, overdenture abutments, removable partial dentures, malocclusion, cervical non-carious lesions, tipped teeth, which make certain areas of teeth inaccessible for cleaning. ${ }^{21}$

Cardiovascular diseases have also been associated with higher caries experience, particularly in individuals of 80 years or older. Older people with hypoalbuminemia are at considerable risk of root caries. ${ }^{22}$ Diseases like Sjögren's syndrome, diabetes mellitus also increase caries risk status. ${ }^{19}$. Drugs used for managing these systemic conditions, unattended oral hygiene and altered oral flora may be the contributing factors for elevated root caries level in such individuals. Low indices of socioeconomic status have been associated with an increase in caries due to reduced access to care. Another behavioral risk factor is tobacco use. Smoking is associated with periodontal diseases and gingival recession, and chewing tobacco contains fermentable carbohydrates. ${ }^{23}$ Other behavioral risk factors include consumption of alcohol/narcotics. Males are more often affected by root caries than females. Patients with physical disabilities or with limited manual dexterity for cleaning their teeth are also at a high risk of root caries. Traumatic tooth brushing habits render the retained dentition susceptible to root surface caries. ${ }^{24}$

\section{Prevention of root caries}

Measures to prevent root caries can be categorized into 3 levels - primary, secondary and tertiary prevention. Primary preventive measures help prevent the occurrence of the disease. This can be done at the population level or individual level. Measures at the population level include water fluoridation, whereas individual measures include reducing or removing risk factors and enhancing protective factors. Secondary preventive measures help slow down or arrest an ongoing disease process. In the case of root caries these measures include remineralization/minimal restoration of carious lesions. They help remineralize incipient lesions and prevent the development of new lesions. Tertiary preventive measures include placing extensive restorations so as to prevent further disease-related deterioration of the tooth and to return it to normal function. Preventive and restorative options based on the risk status of the individual are presented in Table $1 .^{21,25}$

In clinical practice, primary preventive measures to prevent root caries are significant, since restorative treatment of such lesions is extremely challenging and may lead to tooth loss in most cases due to recurrent caries or the sensitivity of the restored tooth. Therefore, such measures should be taken immediately after the exposure of root surfaces, as root caries progresses faster due to low mineral content of the covering cementum. ${ }^{26}$ Fluoride is a widely accepted preventive agent, since it can interfere with the physiochemical and microbiological proceses of root caries. High fluoride concentration may be necessary to prevent and control root caries compared to coronal caries. ${ }^{27}$ Patient-level preventive measures include taking fluoride supplements regularly, fluoridated toothpaste, xylitol gums/mouthwash, chlorhexidine rinses, diamine silver chloride lozenges, altering dietary habits etc.

Table 1. Experimental groups

\begin{tabular}{|c|c|c|c|c|}
\hline Risk level & Oral hygiene & Root caries & Preventive measures & Restorative material \\
\hline Low & good & no caries in 3 years & reinforce prevention, annual recall & no restrictions \\
\hline Medium & fair & $\begin{array}{l}1-2 \text { lesions } \\
\text { in } 3 \text { years }\end{array}$ & $\begin{array}{l}\text { diet counseling, fluoride toothpaste, fluoride mouthwash, } \\
\text { professional fluoride application, 6-month recall }\end{array}$ & $\begin{array}{l}\text { resin composites, resin modified } \\
\text { glass ionomers, compomers }\end{array}$ \\
\hline High & poor & $\begin{array}{l}\text { more than } 3 \text { lesions } \\
\text { in past } 3 \text { years }\end{array}$ & $\begin{array}{l}\text { monitor microorganisms, modify diet, high-fluoride toothpaste, } \\
\text { sodium fluoride/APF gel daily and chlorhexidine rinse } \\
\text { for 2-4 weeks, xylitol chewing gum, 3-month recall }\end{array}$ & fluoride releasing materials \\
\hline
\end{tabular}


Professional-level preventive measures include the application of topical fluoride gels/varnishes. The list of medications taken by the patient can be checked and less xerogenic drugs can be prescribed or their dosage can be reduced. Salivary stimulants such as pilocarpine can be prescribed. ${ }^{28}$ For the primary prevention of root caries the recommended best choice is $38 \%$ silver diamine fluoride solution professionally applied manually; it is recommended as the most cost saving treatment for root caries prevention in high risk individuals. ${ }^{29}$ If no professional application is possible, the best alternative is the use of self-applied amorphous calcium phosphate (ACP) and fluoride toothpaste daily.

Subjects with risk of root caries should be recommended to use fluoride toothpaste with a concentration between 1000 and 1500 ppm of fluoride as sodium fluoride, monofluoro phosphate or amino fluoride. The daily use of 1100 ppm dentifrice combined with APF (acidulated phosphate fluoride) gel application provides added protection. ${ }^{30}$ Studies have shown that the use of fluoride toothpaste containing $1.5 \%$ arginine and insoluble calcium resulted in the formation of ammonia and increased $\mathrm{pH}$ level of the oral cavity, and thus prevented the development of root caries. Also, arginine helps maintain the normal oral flora and thereby derive the benefits of normal oral flora ${ }^{31}$ Mechanical plaque control methods may require good manual dexterity, which is compromised at old age. Moreover, hypersensitivity is a common problem for elderly people. Therefore, antimicrobial agents may complement mechanical plaque removal for preventing root caries. The use of automated toothbrushes and the daily use of water irrigation devices can also be suggested for root caries-prone patients. In high risk patients who wear dental prostheses avoid placing restoration margins apical to the surrounding tissue to prevent plaque accumulation. ${ }^{28}$

Cavitated root caries that is not easily accessible for cleaning may be restored by minimally invasive techniques. ${ }^{32}$ Fast setting self-cure glass ionomers could be used for such minimal restorations. Regular use of dentifrices containing 5000 ppm fluoride and quarterly professional application of chlorhexidine or silver diamine fluoride varnishes have been found to be effective in decreasing the progression and initiation of root caries. ${ }^{33}$ Silver nitrate and silver diamine fluoride are more effective in arresting active caries lesions and preventing new caries than fluoride varnish. It has antimicrobial activity against Streptococcus mutans and Actinomyces naeslundii found on dentin surfaces and slows down dentin demineralization. ${ }^{34}$ Studies have shown that the use of $10 \%$ sodium hypochlorite removes organic materials and increases the permeability of fluoride ions, and thereby increases the potential of remineralization. ${ }^{35}$ In a 15 -month period study the daily intake of milk supplemented with fluoride and, or probiotic bacteria was found to reverse soft and leathery primary root caries lesions. ${ }^{36}$
Dentin biomodifiers are agents which interact with various extracellular matrix components of dentin and increase their mechanical properties, decrease the biodegradation rate and possibly promote mineral nucleation. ${ }^{37}$ Dentin modifiers, such as $5 \%$ glutaraldehyde, $0.5 \%$ proanthocyanidin and $0.625 \%$ genipin, can modify dentin collagen and increase its resistance to enzymatic digestion by cariogenic organisms. ${ }^{38}$ Grape seed extract contains proanthocyanidin which can be used instead of fluoride during minimally invasive the treatment of root caries. Proanthocyanidintreated collagen matrices resisted enzyme digestion in vivo and in vitro. Also it increased collagen synthesis and accelerated the conversion of soluble collagen into insoluble collagen during development. Grape seed extract also induced cross-links in dentin collagen and increased the ultimate tensile strength of demineralized dentin. ${ }^{39}$ The combined use of proanthocyanidin and casein phosphopeptideamorphous calcium fluoride phosphate (CPP-ACFP) has synergistic effect on root caries remineralization and increases the hardness of root caries. ${ }^{40}$

Coating the root surface with resin-based materials that can release and recharge fluoride may be a simple and effective measure to protect it from physical, chemical and biologic insults. Surface prereacted glass ionomer (S-PRG) fillers incorporated into resinous material, which have the ability to release and recharge fluoride and other ions such as aluminum, boron and strontium, can be used to enhance remineralization and reduce acid attack by oral cariogenic bacteria. RG filler containing resins were found to inhibit bacteria induced $\mathrm{pH}$ drop and formed a hermetic seal on the exposed dentin surface. ${ }^{41}$ Progression of root caries could be inhibited by the application of antibacterial adhesive system containing 12-methacryloyloxydodecylpyridinium bromide (MDPB). Unpolymerized MDPB in the primer solution penetrates deeply into the lesion to kill or inactivate the infecting bacteria. Also, it seals the lesion and prevents caries. ${ }^{42}$

A combination of casein phosphopeptide and amorphous calcium phosphate (CCP-ACP) and photo activated disinfection (PAD) proved to be very effective and holds great potential as a recommended treatment for stabilizing root surface caries in the clinical practice. ${ }^{43}$ Healozone has been proposed as a method of reversing, arresting or slowing down the progression of dental caries. Ozone gas is applied to the carious lesion followed by the use of a remineralizing solution, immediately after the application of ozone. ${ }^{44}$

Carious lesions should be restored taking into consideration the patient's age, health status and symptoms associated with root caries. Before the teeth are restored, root caries must be controlled using preventive measures. The type of restorative material depends on the location, accessibility of margins of the lesion and oral hygiene. Restorative management is challenging due to difficulties in visibility, moisture control, access to carious lesions, proximity to pulp/gingival margin and high organic content of dentine. 
Microleakage and poor marginal adaptation of the restoration or defective margins are the most common causes of failure. Restorative material with high potential for fluoride release as well as uptake should be considered. ${ }^{45}$

The root surface is cleaned with pumice, the excavation of carious tissue is done, and the restoration walls are prepared. Margins and restoration design depend on the restorative material used. Modified composite or resin modified glass ionomer are ideal for restorations in medium risk individuals. Root caries often may extend below the gingival margin, making it necessary to retract the gingiva with a clamp/pack to expose the cervical margin of the lesion or to utilize laser or electrosurgery to recontour the gingiva and obtain access to the lesion. A combined minor periodontal and restorative procedure is relatively simple and when done properly can provide excellent and affordable dentistry in the problematic areas. ${ }^{46}$ The decision to use a particular method of retraction depends upon whether the apical extension of the lesion is located $2 \mathrm{~mm}$ above the height of the alveolar crest. Access can be gained by the use of a retraction cord and cervical clamp like 212, which displaces the soft tissue and exposes the lesion, or by creating a mini flap. ${ }^{47}$ Coverage of a previously carious root with subepithelial connective tissue graft is a very predictable procedure, with results similar to those found in intact roots. This procedure may provide a definitive biological alternative for conventional treatment modalities for root caries. Moreover, the results are more esthetic, biologically acceptable and maintainable. ${ }^{48}$ In search of other effective long-term preventive measures against caries, research is being conducted on developing caries vaccine. The main research target is the mechanism of adherence of Streptococcus, which can be affected by active/passive immunization and the use of DNA vaccines. ${ }^{49}$

\section{Conclusions}

With the development of newer technologies and oral hygiene measures, the incidence of dental caries has been reduced significantly. However, root caries continues to be a major challenge for both the patient and the dentist. It has been found to be a major factor which negatively affects the oral-health-related quality of life in the elderly population. In most cases, when these lesions are diagnosed, they are in the advanced stages, which necessitates the removal of the tooth. Regular dental visits and oral hygiene monitoring is essential in old age to meet this challenge.

\section{References}

1. Schamschula RG, Barmes DE, Keyes PH, Gulbinat W. Prevalence and interrelationships of root surface caries on Lufa, Papua New Guinea. Community Dent Oral Epidemiol. 1974;2:295-304.

2. Sumney DL, Jordan HV. Characterization of bacteria isolated from human root surface carious lesions. J Dent Res. 1974;53:343-351.

3. Aherne CA, O'Mullane D, Barrett BE. Indices of root surface caries. J Dent Res. 1990;69:1222-1226.
4. Beighton D, Lynch $E$, Heath MR. A microbiological study of primary root-caries lesions with different treatment needs. J Dent Res. 1993;72:623-629.

5. Jones JA. Root caries: Prevention and chemotherapy. Am J Dent. 1995;8:352-357.

6. Surmont PA, Martens LC. Root surface caries: An update. Clin Prev Dent. 1989;11:14-20.

7. McIntyre JM, Featherstone JD, Fu J. Studies of dental root surface caries. Aust Dent J. 2000;45,24-30.

8. The role of cementum in root surface caries. Aust Dent J. 2000; 45:97-102.

9. Ellen RP, Banting DW, Fillery ED. Streptococcus mutans and Lactobacillus detection in the assessment of dental root surface caries risk. J Dent Res. 1985;64:1245-1249.

10. Banting DW. Epidemiology of root caries. Gerodontol. 1986;5:5-11.

11. Nisha G, Amit G. Textbook of Operative Dentistry. $2^{\text {nd }}$ ed. New Delhi, India: Jaypee Brothers Medical Publishers; 2013.

12. Katz RV. The $\mathrm{RCI}$ revisited after 15 years: Used, reinvented, modified, debated, and natural logged. J Public Health Dent. 1996;56:28-34.

13. Dye BA, Tan S, Smith V, et al. Trends in oral health status: United States, 1988-1994 and 1999-2004. Vital Health Stat. 2007;11:1-92.

14. Preza $D$, Olsen I, Willumsen T, et al. Microarray analysis of the microflora of root caries in elderly. Eur J Clin Microbiol Infect Dis. 2009;28:509-517.

15. Hashimoto K, Sato T, Shimauchi H, Takahashi N. Profiling of dental plaque microflora on root caries lesions and the protein-denaturing activity of these bacteria. Am J Dent. 2011;24:295-299.

16. Chen L, Qin B, Du M, et al. Extensive description and comparison of human supra-gingival microbiome in root caries and health. PLOS One. 2015;10. doi:10.1371/e 0117064.

17. Shivakumar K, Prasad S, Chandu G. International caries detection and assessment system: A new paradigm in detection of dental caries. J Conserv Dent. 2009;12:10-16.

18. Chi DL, Shyue C. Managing caries risk in adults. Dimen Dent Hyg. 2014;12:36-40.

19. Joshi A, Douglass CW, Jette A, Feldman H. The distribution of root caries in community-dwelling elders in New England. J Public Health Dent. 1994;54:15-23.

20. Lenander-Lumikari M, Loimaranta V. Saliva and dental caries. Adv Dent Res. 2000;14:40-47.

21. Fischer D, Ship JA. Effect of age on variability of parotid salivary gland flow rates over time. Age Ageing. 1999;28:557-561.

22. Shay K. Root caries in the older patient: Significance, prevention, and treatment. Dent Clin North Am. 1997;41:763-793.

23. Yoshihara A, Takano N, Hirotomi T, Ogawa H, Hanada N, Miyazaki H. Longitudinal relationship between root caries and serum albumin. J Dent Res. 2007:86:1115-1119.

24. Ringelberg ML, Gilbert GH, Antonson DE, et al. Root caries and root defects in urban and rural adults: The Florida dental care study. J Am Dent Assoc. 1996;127:885-891.

25. Imazato S, Ikebe K, Nokubi T, Ebisu S, Walls AW. Prevalence of root caries in a selected population of older adults in Japan. J Oral Rehabil. 2006;33:137-143.

26. Shaker Randa E. Diagnosis, prevention and treatment of root caries. Saudi Dent J. 2004;16:84-86.

27. Keltjens $H$, Schaeken $T$, van der Hoeven $H$. Preventive aspects of root caries. Int Dent J. 1993;43:143-148.

28. Rodrigues JA, Lussi A, Seemann R, Neuhaus KW. Prevention of crown and root caries in adults. Periodontol 2000. 2011;55:231-249.

29. Gluzman R, Katz RV, Frey BJ, McGowan R. Prevention of root caries: A literature review of primary and secondary preventive agents. Spec Care Dent. 2013;33:133-140.

30. Schwendicke F, Göstemeyer G. Cost-effectiveness of root caries preventive treatments. J Dent. 2017;56:58-64.

31. Vale GC, Tabchoury CP, Del Bel Cury AA, Tenuta LM, ten Cate JM, Cury JA. APF and dentifrice effect on root dentin demineralization and biofilm. J Dent Res. 2011;90:77-81.

32. ten Cate JM, Cummins D. Fluoride toothpaste containing $1.5 \%$ arginine and insoluble calcium as a new standard of care in caries prevention. J Clin Dent. 2013;24:79-87.

33. Heasman PA, Ritchie M, Asuni A, Gavillet E, Simonsen JL, Nyvad B. Gingival recession and root caries in the ageing population: a critical evaluation of treatments. J Clin Periodontol. 2017;44(Suppl. 18):S178-S193. 
34. Wierichs RJ, Meyer-Lueckel H. Systematic review on noninvasive treatment of root caries lesions. J Dent Res. 2015;94:261-271.

35. Mei ML, Chu CH, Lo EC, Samaranayake LP. Preventing root caries development under oral biofilm challenge in an artificial mouth. Med Oral Patol Oral Cir Bucal. 2013;18:e557-563.

36. Inaba D, Duschner H, Jongebloed W, Odelius H, Takagi O, Arends J. The effects of a sodium hypochlorite treatment on demineralized root dentin. Eur J Oral Sci. 1995;103:368-374.

37. Petersson LG, Magnusson K, Hakestam U, Baigi A, Twetman S. Reversal of primary root caries lesions after daily intake of milk supplemented with fluoride and probiotic lactobacilli in older adults. Acta Odontol Scand. 2011;69:321-327.

38. Bedran-Russo AK, Pereira PN, Duarte WR, Drummond JL, Yamauchi M. Application of crosslinkers to dentin collagen enhances the ultimate tensile strength. J Biomed Mater Res B Appl Biomater. 2007:80:268-272.

39. Jayakrishnan A, Jameela SR. Glutaraldehyde as a fixative in bioprostheses and drug delivery matrices. Biomaterials. 1996;17:471-484.

40. Han B, Jaurequi J, Tang BW, Nimni ME. Proanthocyanidin: A natural crosslinking reagent for stabilizing collagen matrices. $J$ Biomed Mater Res A. 2003;65:118-124.

41. Epasinghe DJ, Yiu C, Burrow MF. Synergistic effect of proanthocyanidin and CPP-ACFP on remineralization of artificial root caries. Aust Dent J. 2015;60:463-470.

42. Ma S, Imazato S, Chen JH, et al. Effects of a coating resin containing S-PRG filler to prevent demineralization of root surfaces. Dent Mater J. 2012;31:909-915.

43. Rolland SL, McCabe JF, Imazato S, Walls AW. A randomised trial comparing the antibacterial effects of dentine primers against bacteria in natural root caries. Caries Res. 2011;45:574-580.

44. Vlacic J, Meyers IA, Walsh LJ. Combined CPP-ACP and photoactivated disinfection (PAD) therapy in arresting root surface caries: A case report. Br Dent J. 2007;203:457-459.

45. Brazzelli M, McKenzie L, Fielding S, et al. Systematic review of the effectiveness and cost-effectiveness of HealOzone for the treatment of occlusal pit/fissure caries and root caries. Health Technol Assess. 2006;10:75-80.

46. Anusavice KJ. Dental caries: Risk assessment and treatment solutions for an elderly population. Compend Contin Educ Dent. 2002; 23(Suppl. 10):12-20.

47. Burgess JO, Gallo JR. Treating root-surface caries. Dent Clin North Am. 2002;46:385-404.

48. Turner EW, Shook LW, Lackey M. Accessing and restoring root caries: A case report. J Tenn Dent Assoc. 2007;87:20-24.

49. Goldstein M, Nasatzky E, Goultschin J, Boyan BD, Schwartz Z. Coverage of previously carious roots is as predictable a procedure as coverage of intact roots. J Periodontol. 2002;73:1419-1426. 